\title{
RACE AND HEALTH DISPARITIES AMONG SENIORS IN URBAN AREAS IN BRAZIL
}

\author{
Antonio J. Trujillo \\ John A. Vernon \\ Laura Rodriguez Wong \\ Gustavo Angeles
}

Working Paper 11690 
NBER WORKING PAPER SERIES

\title{
RACE AND HEALTH DISPARITIES AMONG SENIORS IN URBAN AREAS IN BRAZIL
}

\author{
Antonio J. Trujillo \\ John A. Vernon \\ Laura Rodriguez Wong \\ Gustavo Angeles \\ Working Paper 11690 \\ http://www.nber.org/papers/w11690
}

\author{
NATIONAL BUREAU OF ECONOMIC RESEARCH \\ 1050 Massachusetts Avenue \\ Cambridge, MA 02138 \\ October 2005
}

The views expressed herein are those of the author(s) and do not necessarily reflect the views of the National Bureau of Economic Research.

C2005 by Antonio J. Trujillo, John A. Vernon, Laura Rodriguez Wong, and Gustavo Angeles. All rights reserved. Short sections of text, not to exceed two paragraphs, may be quoted without explicit permission provided that full credit, including (C) notice, is given to the source. 
Race and Health Disparities Among Seniors in Urban Areas in Brazil

Antonio J. Trujillo, John A. Vernon, Laura Rodriguez Wong, and Gustavo Angeles

NBER Working Paper No. 11690

October 2005

JEL No. J1, I1, I3

\begin{abstract}
$\underline{\text { ABSTRACT }}$
White seniors report better health than Black seniors in urban areas in Sao Paulo, Brazil. This is the case even after controlling for baseline health conditions and several demographic, socio-economic and family support characteristics. Furthermore, adjusted racial disparities in self-reported health are larger than the disparities found using alternative measures of functional health. Our empirical research in this paper suggests that the two most important factors driving racial disparities in health among seniors (in our sample) are historical differences in rural living conditions and current income. Present economic conditions are more relevant to racial disparities among poor seniors than among rich seniors. Moreover, racial differences in health not attributable to observable characteristics are more important when comparing individuals in the upper half of the income distribution.
\end{abstract}

Antonio J. Trujillo

College of Public Affairs

University of Central Florida

atrujill@mail.ucf.edu

John A. Vernon

University of Connecticut

Department of Finance

2100 Hillside Road

Storrs, CT 06269

and NBER

jvernon@business.uconn.edu

Laura Rodriguez Wong

CEDEPLAR/UFMG

Gustavo Angeles

College of Health

University of North Carolina at Chapel Hill 


\section{Introduction}

Policy makers today consider the social exclusion, or marginalization, of ethnic groups to be one reason for the existence of disparities in human capital in Latin America. Racial and ethnic inequality in the provision and utilization of health care, taken together with the global issues of controlling cost and increasing access, is frequently reported as one of the most important problems facing the health care sector in Latin America (WHO 2001).

In Brazil, these racial disparities in health status have been widening. For example, at all ages, Blacks report higher mortality rates than Whites, lower life expectancies, lower survival rates for all causes, and a higher incidence (and earlier onset) of disease. Racial disparities in health have been persistent and broadening at older ages despite economic progress and overall increases in health (World Bank Report 2003). The evidence suggests that the population of Brazil is aging at a faster rate than the populations of most developed countries (Vaupel 1998, Seabrook, 2003). Health care in old age absorbs an everincreasing share of GDP, and the demand for increased services for seniors is increasingly apparent in the region's crowded urban areas. At the same time, the Brazilian public has become aware of growing racial disparities in health in old age and in the medical care available to the elderly.

In this paper we will first examine the health disparities among the elderly in Sao Paulo, the largest city in Brazil. Following this, we will present a framework that may help explain and better understand the sources of these health differences. Lastly, we recommend policies initiatives that may help mitigate these racial disparities in health. Our analysis is conducted using the 
newly available $\mathrm{SABE}^{1}$ dataset which addresses several dimensions of individual health.

Two racial groups are compared: the control group includes those individuals who declared themselves "White", while the treatment group includes those individuals who declared themselves "Black," as well as those individuals who reported themselves to be "Mulatto". Regardless of this classification, one should keep in mind that race may be a difficult variable to measure. Race and ethnicity are, to some extent, individual characteristics that may have elements in common with nativity and even religious affiliation ${ }^{3}$. For instance, two individuals in different race groups could share similar cultural values because of their common country of origin. Furthermore, the self -identification of race could differ from the group identification of an individual's race. Finally, classification of individuals with mixed parents could pose some additional problems in the assignment of race. Assuming that race can be measured with some degree of accuracy, it has been identified in health research as an important risk factor that measures a combination of socio-economic, cultural and biological characteristics, which explain the accumulation and deterioration of health capital over the life span of an individual (Lillie-Blanton, M and Lavesist, 1996).

\footnotetext{
* Mailing address: 400 East Colonial Dr, Apt. 802, Orlando, FL 32803, USA.

Telephone: (407) 823-4238; Fax: (407) 823-6138

E-mail: atrujill@mail.ucf.edu.
}

\footnotetext{
${ }^{1}$ The acronym SABE is short for Salud, Bienestar, and Envejecimiento-Health, Well Being, and Aging, a 2000 survey conducted in 7 representative cities in Latin American countries. The SABE web page (www.ssc.wisc.edu/sabe) lists complete information on the agencies and researchers who participated in the project.

${ }^{2}$ The SABE dataset does not include the interviewer's perception of an individual's race. The survey relies on an individual's self-perception of race based on the following question... "could you please tell me what your race and ethnic background is"?. Telles (2002) investigates the disparities that may arise between interviewers' and respondents' classification of race. This study reports that answers are consistent in almost $80 \%$ of all cases. Individual factors such as gender, age, education, and region could explain partially the inconsistencies. For instance, a more educated person tends to "whiten" her race; but this result could vary with region.

${ }^{3}$ According to Mejia and Moncada (2000), for the purpose of the national census, ethnic groups have been identified in Brazil using a self-identification question since 1982. The given options are Branca (White), Preta (Black), Parda (Brown), Indigena, Amarela (Yellow which includes individuals of Asian origin) and others.
} 
Figure $1^{4}$ shows the gradient of health deterioration by age group according to race in Sao Paulo. As expected, for both Whites and Blacks, health deteriorates as an individual ages. The gap in health differences between Whites and Blacks declines in older groups. Nevertheless, at all ages, Blacks have poorer self-reported health status than Whites. Surprisingly, the differences are less pronounced when one uses ADL and IADL as measures of health. The reduction in the differences between racial groups with increasing age could be the consequence of a cross-over in the mortality rate among Blacks and Whites at later ages.

To better understand the reasons for these differences in health, it needs to be determined whether the health gap among race groups remains after one controls for the relevant variables, other than race, that are hypothesized to impact health status. Adding successive control variables to the analysis will help identify the channels through which race may influence health in old age (LaVeist 1994 and Wagstaff \& Van Doorslaer, 2000). Observed racial disparities in health could be due to three factors: differences in the level of endowment or observable individual characteristics (e.g. White seniors may have higher income and education than Black seniors); differences in the marginal effect that each factor has on an individual's health; and differences in unobservable individual characteristics (e.g., genetic composition). This analysis also presents a framework for understanding the underlying factors that account for racial disparities in health among seniors.

It has been documented in the health economics literature (see Wenzlow et al., 2004, Wagstaff et al., 2003 and Case and Deaton, 2004, among others) that even at older ages the health of an individual is related to her or his socioeconomic condition. Clearly, the relationship extends in the opposite direction; at more advanced ages, one may expect that health affects income. (See Smith, 1998). Numerous studies have suggested that there is a link between health and labor outcomes in terms of productivity, labor supply and wages. (See Strauss

\footnotetext{
${ }^{4}$ Larger numbers indicate better health in terms of SRHS, ADL and IADL.
} 
and Thomas, 1998, for a discussion of this topic.) This complex relationship between income and health has been reported in both developed and developing countries, and across different measures of income and health. The expected socio-economic gradient in health also has been documented using aggregate community data. (See Krieger et al., 2003, for an example in the U.S.) Strong correlations between income conditions and racial disparities in mortality have been documented in the literature. Because Whites tend to report higher income than Blacks, one might expect that there would be a gap between the health of Whites and Blacks across income rankings, but this gap tends to decline as income increases.

Figure 2 shows a relationship partially consistent with these previous empirical findings. For the case of Sao Paulo, Brazil, both Whites and Blacks report an increase in self-reported health between the first quartile and the fourth quartile of the income distribution. Interestingly, the relationship between income and health is not linear. Blacks in the third quartile of the income distribution have lower SRHS than Blacks in the second quartile. This gradient in health and income level at the extremes of the distribution is also consistent for ADL and IADL measures. Whites also report higher income than Blacks, which may in part explain the gap between self-reported health for these groups. However, these differences in health may also be driven by other differences across racial groups, such as education, occupation history, and/or past health status. Furthermore, different measures of income may create alternative rankings of individuals. For instance, using wealth as an alternative measure of well-being may result in different disparities in the health of Whites and Blacks.

Socio-economic differences have been reported to be crucial risk factors in explaining racial disparities in health, but they are not the sole factor (William, 2005). Differences in the distribution of diseases among Whites and Blacks (Figure 3) could be due in part to a genetic predisposition. Blacks are more likely than Whites to report strokes and psychiatric problems, while Whites are more likely than Blacks to report having arthritis and cancer. In addition, the marginal benefit from a particular medical treatment could differ by race due to a specific 
genetic condition (e.g. organ transplants are more successful in Whites, perhaps because Blacks have greater genetic variation, making matches more difficult). However, the vast majority of the literature on racial disparities in health suggests that differences in socio-economic and cultural environments rather than racial differences in biological factors provide the main explanations for these disparities. (For a review of the literature, see Smedley, B, Stith, A and Nelson, A., 2002.)

In addition to differences in socio-economic conditions, and genetic predisposition, other factors associated with geographic marginalization, the mechanisms of racism, social context, and access to medical care and quality have been linked to racial disparities in health. Discrimination could reduce access to the labor market and to other goods and services which, over time, may affect the health of the individuals. Furthermore, discrimination itself may affect the mental health and well-being of an individual by leading to stress, depression, or other mental problems. Blacks may also suffer from discrimination in access to certain health services. Finally, the social context may influence the variation in timing of care and risk aversion among Blacks and Whites. Notice that the roles of discrimination and social context could differ by cohort. Individuals of different ages could have different life experiences in terms of what race meant in their particular social context.

In this paper, we will address three fundamental questions. (1) Are the racial disparities in health as displayed in Figure 1, Figure 2 and Figure 3, eliminated once one controls for the relevant observable individual characteristics included in the SABE database?; (2) What are the main sources of these racial disparities in health?; and (3) Are differences in endowment equally relevant to racial disparities in health among poor Black and White seniors compared to race disparities in health among rich Black and White seniors?

In the next section, we will describe in more detail the racial disparities in income, wealth, and health. Section III documents additional differences between Whites and Blacks besides those differences in income and wealth that could 
account for the racial disparities in health among the elderly in Sao Paulo, Brazil. Section IV presents the econometric strategy to disentangle the effect of differences in endowment, or observable individual characteristics, from the effect of differences in the marginal impact of each risk factor. Section $\mathrm{V}$ presents the main findings; and section VI concludes and establishes the main policy implications we draw from these results.

\section{The Extent of Racial Disparities in Health and Income Among the Elderly in Sao Paulo, Brazil}

Table 1 presents weighted summary statistics of the disparities in health conditions by gender for Whites and Blacks in old age. This preliminary analysis helps to motivate the development of a full econometric model to explain the effects of race on health inequalities. As Table 1 shows, for both males and females, SRHS is better and the ADL and IADL indices are higher among White seniors than Black seniors. Black females report the lowest functional health status among all groups. Although not shown, these differences persist across all age groups. The gradients of health deterioration differ between the two racial groups. For instance, SRHS declines at a slower rate for Black seniors than for White seniors.

Black females are more likely to report life-threatening conditions including hypertension, diabetes, and stroke, while White females are more likely to report cancer and lung disease. Black males are more likely to report hypertension and stoke. Hypertension is usually associated with other dangerous medical conditions that differ by race such as stress and obesity. A higher prevalence of hypertension and diabetes are also factors that may explain the higher prevalence of stroke among Black males. These differences in health conditions are consistent with reports of race disparities in health among the elderly in the U.S. Williams (2005) reported a higher unadjusted mortality rate for Blacks than for Whites for several causes of death: heart disease, cancer, stroke, hypertension, and diabetes, among others. Day (1990) also reported that ethnic 
minorities are more likely to inherit blood disorders, coronary heart disease, diabetes, and perinatal mortality.

Interestingly, the lower prevalence of some disabling conditions among Blacks in the SABE data set may be the consequence of later diagnoses of disease. Yet, both Black males and Black females are more likely than White males and females to report a fall in the last 12 months; and Black males are twice as likely to report an incontinence problem as White males. Taking these results together suggest that Black seniors may have more severe untreated health problems than White seniors. This delay could be related to less frequent use of medical services and lower quality of care available for Black seniors. As Table 1 shows, Blacks are less likely to use hospital and physician services. Factors related to access to healthcare and quality could be additional underlying explanations for these differences in health.

Blacks are more likely than Whites to report lower cognitive scores ${ }^{5}$ and higher prevalence of emotional, nervous or psychiatric problems that could translate into a diminished ability to conduct their normal activities and to seek medical care. The lower mental health status among Black seniors could be due to chronically higher levels of stress. These results contradict findings reported in the U.S., where Black seniors are more likely to report better mental health than White seniors (Smedley, Stith, and Nelson, 2002).

Weight and height have also been suggested as measures of individual's health. Using time-series data from developed and developing countries, greater height and weight have been consistently associated with lower mortality rates. The main advantage of these indicators is that errors measuring these variables would not be correlated with any individual's characteristics. As expected, on average, males are taller and heavier than females; however, once one controls for gender, White and Black seniors show very similar height and weight.

\footnotetext{
${ }^{5}$ In the SABE survey, the evaluation of an individual's cognitive capacity was performed combining the Mini Mental State Examination developed by Folstein et al., 1975 with the Pfeffer Scale (1982).
} 
Exploring income and wealth differences among racial groups could be informative in disentangling disparities in functional health and morbidity outcomes among racial groups. Contemporaneous income and wealth correlate directly with an individual's present health (e.g., economic status may alter an individual's choice of risky behavior, an individual's level of investment in preventive healthcare, or determine one's living conditions); those who are poor have fewer resources to afford healthcare or health insurance. Fortunately, the SABE data set contains information about an individual's total financial resources, from both working and non-working sources, as well as a measure of total assets in the household. The wealth variable provides useful information regarding available financial resources in the long-run, particularly in the case of seniors who are already retired and report no working income. This variable was constructed using a principal component index of a list of assets in the household. The income variable was constructed by the summation of income from the following sources: current salary if she/he is working; resources coming from retirement funds or pensions, resources from family members, rental or banking income, and income from social welfare subsidies. Wealth and income measures were both adjusted for household size.

Table 2 shows that a Black senior in Sao Paulo is more likely to report lower income as well as lower wealth than a White senior ${ }^{6}$. Furthermore, a Black senior is more likely to be in the lower half of the income and wealth distribution than a White senior. These findings are consistent with other results reported for Brazil. For instance, Olinto \& Olinto (2002) report that regardless of age, Black and Brown women have less education, lower family income, and poorer housing conditions than White women. Burgard (2004) reports that the geographic history of slavery and European immigration lead to a concentration of Whites in more affluent and metropolitan areas, while Non-Whites were more likely to live in poor and less developed areas. Although the information is not reported in the

\footnotetext{
${ }^{6}$ The sampling design in the SABE data set accounts for potential problems of under-representation in the final sample of individuals over 80 years of age as well as institutionalized individuals. Thus, the sample represents all seniors in Sao Paulo, Brazil.
} 
SABE data set, it has been reported elsewhere (Beato, 2004) that the racial gap between household income and wealth also exists during early childhood and working years. Beato (2004) also compares Blacks and Whites using the Human Development Index (which is an index based on income, education and life expectancy); Blacks report lower HDI than Whites, and no State reports a higher HDI for Blacks than for Whites. According to the same author, poverty (measured by per capita income) is concentrated in the Black community and remained stable over the past ten years. Blacks represent $63 \%$ of the poor population in Brazil. The current racial disparities in health among the elderly could be the consequence of accumulated differences in income and wealth during earlier years.

Table 3 indicates that higher income and wealth translates into better SRHS, ADL and IADL scores. Poorer people are more likely to report higher morbidity than affluent people. This strong correlation between income, wealth and functional health status remains when one looks within each race. According to these findings, a poor (based on income and wealth) White senior has a better SRHS than a poor Black senior. Likewise, a wealthy White senior has a better SRHS than a wealthy Black senior (based on income as well as a wealth index). However, one should keep in mind that SRHS is a measure adapted to each individual's reality; therefore, there may be individual differences in self-perception of poverty and personal health within seniors of different races. Furthermore, measurement errors in SRHS could be correlated with socioeconomic conditions and education.

Despite the fact that a strong association between income and health exists in the data, these findings are not conclusive evidence of the causal effect between income and health. Feedbacks from health to income may still be present even at old ages. For instance, as shown in Table 4, individuals who report poor health have lower wealth than individuals who report very good and excellent health. Individuals in poor health could be more likely to retire earlier, which in time explains fewer available financial resources. The same positive 
gradient between health and financial resources also happens when one considers income.

In sum, the previous analysis suggests that there are important racial disparities in health, income, and wealth. Yet, the racial disparities in health among the elderly reported in Table 3 could reflect a complex web of factors that interconnect differences in income, wealth, and other individual characteristics. Reverse causation from health to income could also be present in the data.

\section{Other Potential Demographic, Socio-economic, Family Support and Baseline Health Differences Among Race Groups}

Despite income level, other individual and community characteristics may also influence these racial differences in health. Table 5 presents a comparison of White and Black demographic, socio-economic condition, family support and baseline health conditions.

Blacks and Whites have similar age and gender compositions. Also, a similar percentage for both race groups report living alone. Given these similarities, one might expect that the main racial disparities in health are not driven by differences in age, gender, or even living alone. Nevertheless, one should keep in mind that although the age and gender composition of both racial groups is similar, an additional year of life could impact the health deterioration of White seniors differently from Black seniors. Gender may play a role in the racial disparities in health, since females are more likely to live longer than males. Furthermore, widowhood could also explain the disparities in health; for instance, a Black widow may report a different health status than an asset-similar White widow.

Black seniors are more likely to report themselves to be immigrants and less likely to be married. The ethnic background of an individual could help to explain variations in health both within-race and between-race (LaVeist, 1994). Individuals of the same race but from different countries of origin could have 
different dietary practices that affect their health. Current marital status could have a different protective effect on health by race among the elderly. Rushing et al., 1992 reported that marriage is more beneficial for White women than Black women.

Table 5 also shows that Black seniors are less educated and report a lower literacy rate than White seniors. Less educated individuals could have less knowledge about medical treatment and the risk factors associated with certain behavior, be less able to provide self-care to prevent future health problems, and be less aware of environmental risks. Also, more years of education translate into better economic conditions, which may also affect an individual's health. It is important to keep in mind that education in the SABE dataset is based on years of education attained; we do not have a way to control for quality of education.

According to the World Bank Report (2003) for Brazil, Blacks of working age had less education, higher unemployment rates, were more likely to be employed in the informal sector, had fewer assets, reduced access to public services and occupied lower positions in the occupational structure of the society. ${ }^{7}$ Taken together, these factors may imply that life experiences for Blacks are less positive than the experiences of Whites. This could be relevant, since the cohort of individuals included in this analysis are men and women born in the early decades of the last century, in a context where education, employment and other social opportunities were less available to Black individuals in Brazil than they are now.

Although not shown in Table 5, White seniors are more likely to be currently employed than Black seniors. It has been reported in the literature that seniors working outside the home tend to be healthier than non-workers. This effect has been established to be different for Black and White seniors (Waldron and Jacob, 1989). Furthermore, previous studies found that job satisfaction and

\footnotetext{
${ }^{7}$ Some researchers have used type of occupation as a proxy for current socio-economic conditions for the elderly. However, problems associated with measurement of the variable during the senior years, and racial variation in the role of each occupation on an individual's health suggest that a better alternative to capture the impact of available economic resources on an individual's health would be to use wealth and total income.
} 
type of job were mediators of the impact of employment on an individual's health. Interestingly, Rushing et al., 1992, reported that employment was a much better predictor of health for Blacks than for Whites. Yet, this relationship could also be causal, from health to employment status. Healthier people could be more likely to work longer hours and have higher earnings. A sick senior may be inclined to leave the work force in order to receive government financial support.

Exploring the data, one finds that both races have a similar proportion of individuals with public insurance. In Brazil, there are explicit policies to guarantee access to medical care to all seniors. Healthcare is heavily subsidized in the public sector and usually can be purchased at very low, or zero cost. However, Whites are more likely than Blacks to report having private health insurance (See Table 5). In this context of universal access, the availability of private health insurance could imply access to better quality of healthcare, and better health outcomes for White seniors than for Black seniors.

Differences in access to healthcare due to low income or lack of health insurance may be associated with poorer health outcome. Even after adjusting for racial inequalities in socio-economic conditions, circumstances at both the provider and the patient level could create potential sources of racial disparities in access to healthcare. Availability of insurance could make a specific patient more attractive than another. On the other hand, geographic areas with low reimbursement rates from insurance companies might reduce the quality of supply where Blacks and poor individuals are more likely to live. Using the SABE data set, we could not evaluate the supply factors that may explain the observed racial inequalities in healthcare.

Black seniors have a larger number of people living with them, as well as larger numbers of siblings. Given the potential positive effect on health of larger numbers of household members, one may argue that these differences in endowment of family support could mitigate the racial disparities in health that would have otherwise existed. On the other hand, larger household size may imply that more individuals are dependent on the income of the seniors. As a 
consequence, the net effect of larger families on health could be mitigated. This is potentially the case in Brazil where many households depend solely or mostly on the income of senior individuals. As Table 5 shows, Black seniors share their income with more individuals than do White seniors (2.68 vs. 2.29).

Interestingly, Blacks are more likely than White seniors to be past or present smokers, come from a poor family background, have worse health during the first 15 years of their life, and suffer from starvation during their first 15 years of their life. Caloric intakes predict better health and greater longevity if one survives the first years of life. All of these factors clearly have a long-lasting negative impact on an individual's health over his lifetime. In their seminal article, Rosenzweigh and Shultz (1983) developed a model that incorporates how these past family background factors, which often arise during childhood, may impact an individual's health. Contemporaneous racial disparities in health and health-related behavior could be due to present differences in income and wealth between both races, but they also may be due to the cumulative effects of initial disadvantages in environment and socio-economic conditions during early childhood.

\section{Conceptual framework and empirical strategy}

\section{A) Conceptual framework}

In this research, we will implement the conceptual framework proposed by LaVeist (1994). In that framework, race is a latent (unobserved) factor, and skin color is the most common manifest indicator. Societal norms determine how an individual's race is derived from his or her skin color. It is common for an individual to self-identify as one race based on his or her cultural ties and yet have another race ascribed to her/him based upon outward appearance, for example, upon admittance to a hospital. In LaVeist's view, risk exposure, illness factors, and both societal and cultural elements are presumed to affect an individual's observed health outcome in ways that may coincide with, or span race. Societal factors refer to external elements of an individual or household 
which affect health (e.g., poor sanitation in poor communities, rate of homicide, and availability of other public services or access to medical care and quality of care). Cultural factors refer to internal elements related to individual or intragroup behavior (e.g., dietary practices, smoking, drinking, or the custom of providing a home to one's parents). Risk exposure captures environmental elements such as the geological condition of an area, or the availability of resources such as water and air, among others. Illness factors capture biological conditions such as genetic predisposition and/or risk exposure to specific illnesses. In this framework, there is an assumption of homogeneity within socioeconomic and demographic groups. The key contribution of this conceptual framework is that the most important manifest indicator may or may not be the one normally associated with race in a society. For example, societal and cultural factors may differently influence the health outcomes of a "white" individual of European background and those of another "white" individual whose skin color is the same as the first, but whose background is indigenous.

To implement this framework empirically, we will follow the model specification suggested by Wagstaff and van Doorslaer (2000). For estimation purposes, a model where the latent variable race is measured with an error term is considered. For simplicity, instead of presenting one health equation for each racial group, one structural health equation for the entire population (linear in its parameters), is presented here:

$$
\text { Health }=\beta_{0}+\beta_{1} \text { Race }+\beta_{2} \text { Control }+\beta_{3} \text { Control } \times \text { Race }+\mu
$$

The measurement error in the population is due to the differences between race and the skin color indicator, and is defined to be: $\varepsilon=$ Skin-Race. Therefore, the equation to be estimated will be:

$$
\text { Health }=\beta_{0}+\beta_{1} \text { Skin }+\beta_{2} \text { Control }+\beta_{3} \text { Control } \times \text { Skin }+\eta
$$


where skin is the manifest dummy indicator of race, control is a vector of current and cumulative observable random variables, the last variable in the series represents a vector of the interaction between the dummy variable skin and each relevant observable variable, and $\eta$ is the error term, which accounts for unobservable individual characteristics in health $(\mu)$ and the error in measurement $(\varepsilon)$. Notice that one may estimate a different equation for each race, and therefore the interaction between covariate and skin is no longer necessary. Examples of variables that measure current information include: current marital status, age, gender, individual income, household assets, occupation, age at retirement, family support, and the number of children. Variables that measure cumulative effects include, among others: number of past marriages, past health conditions and occupational history.

The parameters to be estimated are $\beta_{0}, \beta_{1}, \beta_{2}$, and $\beta_{3} . \beta_{2}$ and $\beta_{3}$ are vectors of parameters themselves; how many parameters are included in each depends on the number of control variables incorporated in the model. It is important to realize that running equation (2) with only the skin variable will give biased estimates of racial disparities in health. Using additional control variables one can determine the sources of health disparities. For instance, if the influence of the skin variable declines after controlling for socio-economic condition, one may conclude that the initial aggregate racial disparities in health are due to differences in socio-economic characteristics among the racial groups.

\section{B) Econometric strategy}

Two approaches are implemented in this analysis. First, a multi-stage analysis similar to the one proposed by Wagstaff and van Doorslaer (2000) helps to pinpoint the effect of each vector of covariates on racial disparities in health. Second, the previous framework is used to explore the sources of racial disparities in health using the Oaxaca-Blinder decomposition. Table 6 lists each vector and the list of variables inclusive in each. One should notice that these 
covariates capture past and present individual characteristics that affect the health of White and Black seniors.

For the first part of the analysis, Equation (2) is estimated for three dependent variables, SRHS and the ADL and IADL indices. Six estimations are performed. The first set of estimates uses the skin variable with no controls. A second set of estimates uses skin plus the vector of basic individual characteristics such as age, gender, immigration status, marital status and living conditions. The third, fourth and fifth sets of estimates sequentially incorporate, along with skin and the vector of demographic characteristics, each of the remaining vectors. For instance, the third set of estimates includes the following: the skin variable, the vector of individual characteristics and the vector of socioeconomic characteristics. The last set of estimates includes the skin variable with all of the vectors used in the empirical analysis. Given the size of the treatment and control groups, the estimation will not be conducted separately for males and females. Simple OLS models will be implemented.

The second approach (Oaxaca-Blinder decomposition) also takes advantage of the framework developed in the previous section. In particular, the health equation (2) is first estimated separately for each skin group. Then the method quantifies the variation in health according to three sources: (i) differences coming from each covariate (i.e. variation in endowment); (ii) differences coming from the marginal effect of each risk factor on the health of White and Black seniors (i.e. variation in marginal effect); and (iii) unexplained differences coming from non-observable covariates (i.e. variation in the constant model). Lastly, in this analysis, calculations of the proportion of racial disparities due to endowment, marginal effect and differences in the constant of each model are done separately for those individuals in the lower half of the income distribution and for individuals in the upper half of the income distribution.

This analysis uses only the data collected in Brazil. The final response rate in this country was $84.6 \%$, which included a total of 2,142 observations in the database. For more details of the sampling design, see the User's Manual 
for the SABE databases (Pan American Health Organization). Table 6 describes all dependent variables, the independent skin variable, and some of the control variables to be incorporated in our statistical analysis.

\section{Sources of racial disparities in health}

\section{A) Multi-stage analysis}

Table 7 shows the estimated coefficient for the skin variable (i.e., the proxy for race) under six scenarios. When one controls only for the skin variable (Scenario 1), race seems to be an important factor for explaining differences in health only in the case of self-reported health status; for the other two measures of functional health ( $A D L$ and $I A D L$ ), race is not an important explanatory variable. For all measures of functional health, the estimated negative coefficients imply that Black seniors have lower functional health than White seniors. In this section, only the results using SRHS are discussed. SRHS has been reported consistently as a strong predictor of an individual's subsequent morbidity and mortality (Allison and Foster, 2004; Sadana, 2001, and Strauss and Thomas, 1998). This strong relationship between SRHS and subsequent mortality has been attributed to the fact that SRHS may capture the onset and severity of future medical conditions (Sadana, 2001; Thomas and Frankenberg, 2000).

As initially expected, Black seniors have a lower SRHS than White seniors even after controlling for fundamental individual characteristics (Scenario 2). The overall effect of race on health is thus less than in previous estimates. Since the control and treatment groups are very similar in terms of gender, age, and living alone status, this result suggests that the differences between Black and White seniors, in terms of the protective effect of marriage as well as in terms of immigration diversity, could play a role in explaining the racial disparities that are primary interest to us. Since the skin coefficient is still significant, one may argue that there are still other factors that account for these disparities. 
When one controls for different dimensions of the economic resources available, the effect of race on health is reduced. According to our results (see Scenario 3), reducing present socio-economic differences in education, literacy, income, wealth, insurance availability and home ownership (among other socioeconomic factors) would reduce the racial disparities in health more than they would be affected by reducing race differences in endowment related to family support and baseline health conditions. This suggests that much of the racial difference in health among the elderly comes from current socio-economic conditions. Yet, even after controlling for socio-economic differences among these Brazilian seniors, race remains an important factor for explaining the variation in health across senior individuals. Finally, given the cross-sectional nature of the dataset, it is not possible to establish the exact causal pathway between socio-economic conditions and health.

Incorporating control variables for family support conditions also narrows the health differences. In this calculation, the skin coefficient declines from - 0.329 to -0.282 . Interestingly, in this case, since Black seniors have stronger family support than White seniors, we might expect that the skin coefficient would be of a higher magnitude (in absolute value) than the race coefficient in Scenario (2). Instead, this result suggests that weaker family support, having more siblings, may have a protective effect on the health of White seniors. Although the SABE dataset does not have the necessary variables to test this hypothesis, this result may imply that White seniors who are already in good health tend to stay in smaller households. On the other hand, larger households could imply that the help among household members is diffused away from the seniors in the house and shared among the rest of the family members.

As previously mentioned, Black seniors tend to come from poorer environments, have a poorer nutritional status, and face more severe health problems early in life than do White seniors. Controlling for initial baseline health also reduces the racial disparities in health among seniors. These results are consistent with previous research in the U.S. where empirical findings suggest that health among seniors is partially explained by living conditions in the first 15 
years of an individual's life. Yet, race is still an important risk factor for explaining health variation across these seniors after accounting for baseline conditions.

Racial health disparities do not disappear even if one controls simultaneously for all covariates in the model; the estimated skin coefficient declines but is still statistically significant at -0.164 ( $p$ value $<0.01$ ). This suggests that Black seniors report lower SRHS even after taking differences in endowment into consideration. This remaining gap in health between the two races comes from unobservable individual or community characteristics which are not fully captured in the SABE data. For instance, one might argue that Blacks have less access to medical care and good quality of care which, in time, explains the remaining disparities in health and health outcomes. Social discrimination and geographic marginalization could also play a role in explaining the racial gap. Alternatively, the estimated race coefficient could still be significant because of inherent genetic differences between Blacks and Whites. However, given the cross-sectional nature of the data, we can only speculate about the possible reasons for the remaining differences in health for these Black and White seniors.

\section{B) Oaxaca-Blinder decomposition}

In this section, we will discuss the Oaxaca-Blinder decomposition results. Table 9 summarizes the sources of racial disparities in health when one uses SRHS, ADL and IADL. Table 10 presents the results when the analysis is conducted by income group. One needs to keep in mind, prior to any interpretation, that the number in Table 9 (e.g., for SRHS, it is 14.6) represents the net sum of positive and negative effects of each variable used in the analysis. Although available, the separate result for each variable is not shown. In addition, the second row, Part (a) represents the differences due to coefficients. The third row, Part (b) represents differences in the model constants. In all cases, a positive number indicates an advantage for White seniors, while a negative number indicates an advantage for Black seniors. As in the previous 
case, we will discuss the results as they relate to the self-reported health status indicator.

Based on endowment characteristics, White seniors have an advantage in SRHS over Black seniors. Most of these differences in SRHS come from disparities that favor White seniors in terms of education, wealth and, most notably, differences in living conditions during the first 15 years of life. Surprisingly, the highest contribution to the variation in SRHS attributable to observable explanatory variables comes from the condition of living in a rural area during the first five years of life. The second most important component is the consequence of differences in present wealth between White and Black seniors. According to these results, $48 \%$ of all the differences in health could be attributable to disparities in observable characteristics between White and Black seniors. The remaining disparities in SRHS (52\%) come from variation in the coefficients and differences in the model constants.

Table 8 shows within-race and between-group variation in the determinants of health. One may conclude that the marginal effects of age, immigration and economic status during the first 15 years of life are the main factors that contribute to the variation in health that is attributable to the coefficients (i.e., -114.9, see Table 8). Most of these differences favor Black seniors. At the same time, from Table 7 one should also notice that the marginal effect of most of the variables used in the analysis have the same sign, but differ slightly in magnitude for both races. For instance, wealth has a positive effect on health for both races, but the marginal effect of wealth is similar for Black seniors and White seniors. Interestingly, living in a rural area during the first 5 years of life has a similar negative marginal effect for both races. Therefore, one may conclude that the racial disparities in health from this variable are mainly due to differences in the initial conditions for White and Black seniors. Likewise, differences in socio-economic conditions favor White seniors in terms of initial levels of endowment, but additional levels of these variables would benefit both races in a similar fashion. Finally, as Table 8 indicates, the variation in health 
that is captured in the constant terms favors White seniors rather than Black seniors.

Using the Oaxaca-Blinder approach, one may conclude that a significant portion of the health variation between Black and White seniors shown in Figure 1 and Figure 2 comes from variability in endowment between the races in terms of past and present conditions. Most notably, living in rural areas during the first 5 years of life seems to have long-lasting effects on the health condition of these older Brazilians. As we initially suspected, current wealth and income play a fundamental role in the disparities in health. In other words, these results suggest that eliminating past differences in the living conditions between White and Black seniors, as well as reducing disparities in current income, are the two most important factors for eliminating the current racial disparities in health in this study population. Surprisingly, the marginal effects of socio-economic and past health conditions on an individual's health tend to be very similar for the two races. Clearly, using these data we could not sort out how past living conditions operate to reduce an individual's health. However, earlier living conditions may directly affect the health capital of an individual as well as his or her wages and educational capital over the course of his life, which in time also impacts how an individual's health changes over time.

Now we will ask whether observable characteristics play a different role for individuals in the lower half of the income distribution compared to individuals in the upper half of the distribution. Table 10 presents these results using total income; although not shown, the results are similar when one uses wealth. The variation in SRHS attributable to all explanatory variables for individuals in the upper half of the income distribution is lower than the variation for individuals in the lower half of the income distribution ( $27.5 \%$ vs. $116 \%)$. For both income groups, the differences in endowment favor White seniors. Yet, for individuals in the lower half of the income distribution, wealth and education are the variables that contribute the most to the 14.1 percent variation in favor of White seniors. 
Exploring the variation for individuals in the upper half of the income distribution, one notices that variability in endowment due to observables is not only smaller as a percentage of the total disparities in health, but the source of the disparities also varies with respect to the group at the bottom of the income distribution. In fact, the principal differences in endowment between affluent White and affluent Black seniors (12.2) come from risk factors such as living in rural areas during the first 5 years and self-reported health during the first 15 years of life. The role of current wealth and present socio-economic condition in explaining racial variation in health among individuals in the upper half of the income distribution is smaller than the role among individuals in the bottom half of the income distribution. Furthermore, disparities not attributable to observable characteristics are more significant for reducing the health disparities among wealthy seniors than among poor seniors

\section{VI) Concluding remarks}

This research contributes to the health economics literature in developing countries by presenting evidence of racial disparities in health among seniors in Sao Paulo, Brazil according to functional health status, the prevalence of some chronic and acute conditions, and disabling conditions. Unexpectedly, these results are consistent with the extensive literature on developed countries related to racial disparities in health, where many have argued that some, but not all, of the racial disparities in health could be accounted for by eliminating current socio-economic differences. The aim of this paper was not to identify the causal pathways for each race from health and socio-economic conditions to health. Instead, the goal was to describe potential underlying factors behind the racial disparities in health that we observed.

The fact that inequalities in health among these two races persist even after controlling for several covariates could be a consequence of several factors. To improve the decision-making process for designing policies for seniors, one

important issue we must address is the influence of geographic variation in terms of the availability of care and the quality of care in Sao Paulo among seniors of 
different races. Diverse geographical mechanisms could operate to explain racial disparities in health. For instance, it could be the case that, even after controlling for case mix and other patient characteristics, Black seniors are under-served compared to White seniors. Under-representation of Blacks and minorities as health professionals may result in different treatment patterns for patients of different races. Additionally, Blacks could be more likely to live in areas where the quality of care for all types of patients is lower than in areas where White seniors are more likely to live. Notice that in both cases, a policy to ensure equal access among seniors of different races within the same geographic boundaries would do little to reduce the disparities in health. (See Chandra and Skinner, 2003, for an evaluation of this issue.)

On the other hand, disparities could arise because the quality of health care decisions may differ by race. For instance, Black seniors could be more likely to refuse treatment, poorly follow their prescribed treatment regimen, or even to delay seeking for care. Although using the SABE data set one could not fully explore these hypotheses, the data used in this analysis indicate that Blacks have fewer visits to the hospital and physicians, regardless of the fact that they report a higher prevalence of some chronic and life threatening conditions. In this case, policies to enhance the availability of information would be effective in reducing racial disparities in health among these seniors. Alternative policies could also include greater emphasis on the prevention of those illnesses most prevalent among Blacks seniors, and the development of economic incentives to reduce inequalities in the quality of care provided to Blacks seniors.

In this paper, we also propose a method to unravel the sources of racial differences in health among these Brazilian seniors. According to our results, $48 \%$ of the total differences in SRHS among seniors of both races come from observable individual characteristics. The decomposition indicates that racial disparities are not only the consequence of variation in current socio-economic conditions, but also of variation in living conditions during the first 15 years of one's life. Of particular relevance is living in rural areas during the first 5 years of life, which may have long-lasting effects on elders' health. 
Interestingly, among individuals in the poorer half of the income distribution, race disparities in health could be largely accounted for if differences in present socio-economic conditions were reduced. Among the rich, unobservable characteristics are more relevant to explaining the inequalities in health among White and Black seniors. An important implication of our results is that the health of seniors is mostly affected by past health conditions, in particular, by some conditions which arise during early childhood. The negative consequences of poor conditions and ill health are present over the life cycle and during older ages. These findings have important distributional consequences if it is still the case that Blacks are more likely to come from poorer families.

One should keep in mind that rising income among all seniors--holding income inequalities across races constant- may increase these racial disparities instead of reducing them (see Wagstaff, A. et al., 2003 for a similar argument). Thus, policy makers should be concerned not only with the level of socioeconomic condition of seniors of different races, but also of the level of racial differences in socio-economic conditions. Further research is needed to understand the channels through which reducing socio-economic inequalities impacts racial disparities in health, particularly among poor seniors. For instance, better socio-economic conditions could raise the nutritional status of the elderly, or they could alter their rate of time preferences or their attitudes toward risky behavior such as drinking and smoking.

Finally, our findings also suggest that $52 \%$ of the differences in SRHS between White seniors and Black seniors come from differences not attributable to observable individual characteristics. For policy purposes, it thus could be important to evaluate the unobserved determinants of an individual's health at the community level. For instance, Black seniors may be more likely than White seniors to live in areas where social behavior is not conducive to good health. In general, large cities have communities where minorities tend to concentrate with significant deprivation of resources (Day, 1990). In these communities, crime, poor health, limited job opportunities, and a range of other social issues are interrelated problems. Public officials should work in concert to ensure that these 
services are provided to individuals of all ethnic origins. Over-all improvement of the health and economic conditions of the population would not correct racial inequalities in health unless public officials address ethnic disparities directly.

\section{Acknowledgements}

An earlier version of this paper benefited from comments by Claudia Pereira and Antonio Guiffrida, as well as the participants in a seminar at the Inter-American Development Bank during April, 2005. We also would like to thank Valerie Danesh for assistance in securing some of the data used in this project. The authors take sole responsibility for any remaining errors. We would like to thank the Inter-American Development Bank for the financial support provided for this investigation throughout the Project "Race and Ethnic Inequalities in Health and Health Care in Latin American Countries". We also would like to acknowledge the principal investigators who participated in the SABE project, and the PanAmerican Health organization for providing the data used in this analysis. 


\section{VII) References}

Adda J, Chandola T, Marmot M. 2003. "Socio-economic Status and Health: Causality and Pathway." Journal of Econometrics 112, 57-63.

Allison, R.A. and Foster, J.E. 2004. "Measuring Health Inequalities Using Qualitative Data. “ Journal of Health Economic 23, 505-524.

Banks A, Blundell R, Marmot M, Nazroo J. 2002. "Economic Measures in Health Surveys" . Institute for Fiscal Studies and Department of Economics, UCLA.

Beato, L.B. 2004. "Inequality and Human Rights of African Descendants in Brazil". Journal of Black Studies 34 (6), 766-786.

Burgard S. 2005. "Race and Pregnancy-Related Care in Brazil and South Africa". Social Science \& Medicine, In Press.

Case A. 2001. "Does Money Protect Health Status? Evidence from South African Pensions." Princeton University and the NBER.

Case A, Deaton A. 2003. "Broken Down by Work and Sex: How our Health Declines". Research Program in Development Studies. Princeton University.

Chandra A, Skinner J. 2003. "Geography and Racial Health Disparities". National Bureau of Economic Research, Working Paper 9513.

Corder LS, Manton KG. 1991. "National Surveys and the Health and Functioning of the Elderly: The Effects of Design and Content." Journal of the American Statistical Association, 86 (414), 513-525.

Day M. 1990. "Race and Health of Inner Cities." The Statistician, 39 (2), 157-161.

Deaton A. 1999. "Aging and Inequality in Income and Health. Demographic Trends and Economic Consequences." AEA Papers and Proceedings, 88 (2), 248-253. 
Deb P, Trivedi P. 1997. "Demand for Medical Care by the Elderly: A Finite Mixture Approach." Journal of Applied Econometrics, 12 (3), 313-336.

Ettner SL, Grzywacz J. 2003. "Socio-economic Status and Health Among Californians: An Examination of Multiple Pathways." American Journal of Public Health, 93 (3), 441-444.

Folstein Mf., Folstein S., Mchugh Pr. 1975." Mini-Mental State: A practical Method for Grading the Clinician". Journal Psychiatric Research 12, 189198.

Grossman M. 1972. "On the Concept of Health Capital and the Demand for Health." Journal of Political Economy 80, 223-255.

Krieger N, Chen JT, Waterman, PD, Rebkoff DH, Subrarmanian SV. 2003. "Race/ethnicity, Gender, and Monitoring Socio-economic Gradients in Health: a Comparison of Area-Based Socio-economic Measures---The Public Health Disparities Geocoding Project." American Journal of Public Health, 93 (10), 1655-1671.

Lauridsen J, Christiansen T, Hakkinen U. 2003. "Measuring Inequality in Selfreported Health-Discussions of a Recently Suggested Approach Using Finnish data." Health Economics.

LaVeist, TA. 1994. "Beyond Dummy Variables and Sample Selection: What Health Services Researchers Ought to Know about Race as a Variable." Health Services Research, 29 (1), 1-16.

Lillie-Blannton M, LaVeist T. 1996. "Race/Ethnicity, the Social Environment, and Health." Social Science Medicine, 43 (1), 83-91.

Mejia JA, Moncada G. 2000. "Las Variables de Etnia y Raza Encuestas de Hogares en América Latina y el Caribe." Ponencia Presentada en el Primer Encuentro Internacional "Todos Contamos. Los Grupos Étnicos en los Censos." 
Olinto, M.T.A and Olinto, B.A. 2000. "Race and Inequality among Women: An example in Southern Brazil". Cadernos de Saude Publica 16 (4), 11371142.

Palloni A. 1999. "SABE Project: Health, Well-Being, and Aging in the Latin America and the Caribbean." Pan American Health Organization. Research in Public Health. Technical Papers.

Pappas G. 1994. "Elucidating the Relationships between Race, Socio-economic Status, and Health." American Journal of Public Health, 84 (6), 892-893.

Pelaez M, Palloni A, Albala C, Alfonso JC, Ham-Chande R, Hennis A, Lebrao ML, Leon-Diaz E, Pantelides E, Prats O. 2003. Survey on Aging, Health, and Wellbeing, 2000. Pan American Health Organization (PAHO/WHO).

Pfeffer, R.I., Kurosaki, T.T., Harrah, C, Jr. Chance, J,M., Filos, S. 1982.

"Measurement of Functional Activities in older adults in the community". Journal of Gerontology 37:3, 323-329.

Pritchett L, Summers L. 1996. "Wealthier is Healthier." Journal of Human Resources, 31 (4), 841-868.

Rosenzweig, M.R., and T.P. Schultz. 1983. "Estimating a Household Production Function: Heterogeneity, the Demand for Health Inputs, and Their Effects on Birth Weight". Journal of Political Economy 91:5, 723-746.

Rushing B, Ritter C, Burton RPD. 1992. "Race Differences in the Effects of Multiple Roles in Health: Longitudinal Evidence from a National Sample of Older Men." Journal of Health and Social Behavior, 33, 126-139.

Sadana, R., 2001. "Self-report Versus Observed Health Status: Evaluation of Cross-population Comparability. Prepared for Global Conferences on Summary Measures of Population Health, Geneva: World Health Organization.

Salas C. 2002. "On the Empirical Association between Poor Health and Low Socio-economic Status at Old Age." Health Economics 11, 207-220. 
Seabrook J. 2003. "A World Grown Old." Harvard International Review, 25 (1), 22.

Smedley, B, Stith, A and Nelson,A. Editors, 2002. Unequal Treatment: Confronting Racial and Ethnic Disparities in Health Care. The National Academies Press, Washington, D.C.

Smith JP. 1998. "Socio-economic Status and Health." The American Economic Review 88 (2), 192-196.

Smith JP. 1999. "Healthy Bodies and Thick Wallets: The Dual Relationship between Health and Economic Status." Journal of Economic Perspectives, 13 (2), 145-166.

Smith JP, and Kington R. 2003. Race, Socio-economic Status, and Health in Late Life. National Institute on Aging and The National Institutes of Child Health and Human Development, Working Paper.

Strauss J, Gertler P, Rahman O, Fox K. 1993. "Gender and Life-Cycle Differentials in the Patterns and Determinants of Adult Health." Journal of Human Resources, 28 (4), 792-837.

Strauss, J. and Thomas, D. , 1998. "Health, Nutrition, and Economic Development." Journal of Economic Literature, vol. XXXVI, 766-817.

Thomas, D. and Frankenberg, E. 2000. "The Measurement and Interpretation of Health in Social Surveys". Unpublished manuscript prepared for the World Health Organization Conference on Summary Measures for Population Health, Marrakech, December, 1999.

Uhlenberg P. 1992. Population Aging and Social Policy. Annual Review of Sociology, 18, 449-474.

Telles, E. 2002. Racial Ambiguity among the Brazilian Population. Ethnic and Racial Studies, Vol.25:3, 415-441. 
Vaupel JW. 1998. Demographic Analysis of Aging and Longevity, Demographic Trends and Economic Consequences. AEA Papers and Proceedings, 88 (2), 242-247.

World Bank Latin American and Caribbean Studies 2003. Inequality in Latin America and the Caribbean: Breaking with History. The World Bank, Washington, DC.

World Health Organization. 2001. World Conference against Racism, Racial, Discrimination, Xenophobia and Related Intolerance. Health \& Human Rights Publication Series, 2, August 2001.

Wagstaff A, van Doorslaer E. 2000. "Equity in Health Care Finance and Delivery." Handbook of Health Economics, 1, 1804-1862.

Waldron, I. and Jacobs, J.A. 1989. Effects of Multiple Roles on Women's Health -Evidence from a National Longitudinal Study. Women \& Health 15, 3-19.

Wagstaff, A., van Doorslaer E and Watanabe, N. 2003. On Decomposing the Causes of Health Sector Inequalities with an Application to Malnutrition Inequalities in Vietnam. Journal of Econometrics, 112, 207-223.

William, D. 2005. Racial/Ethnic Differences in Health: 10 Key Facts. Institute for Social Research, University of Michigan. Unpublished presentation.

Wooldridge, JM. 2002. Econometric Analysis of Cross Section and Panel Data. MIT Press. Cambridge, MA. 
Figure 1: White and Black Health Deterioration after Age 60

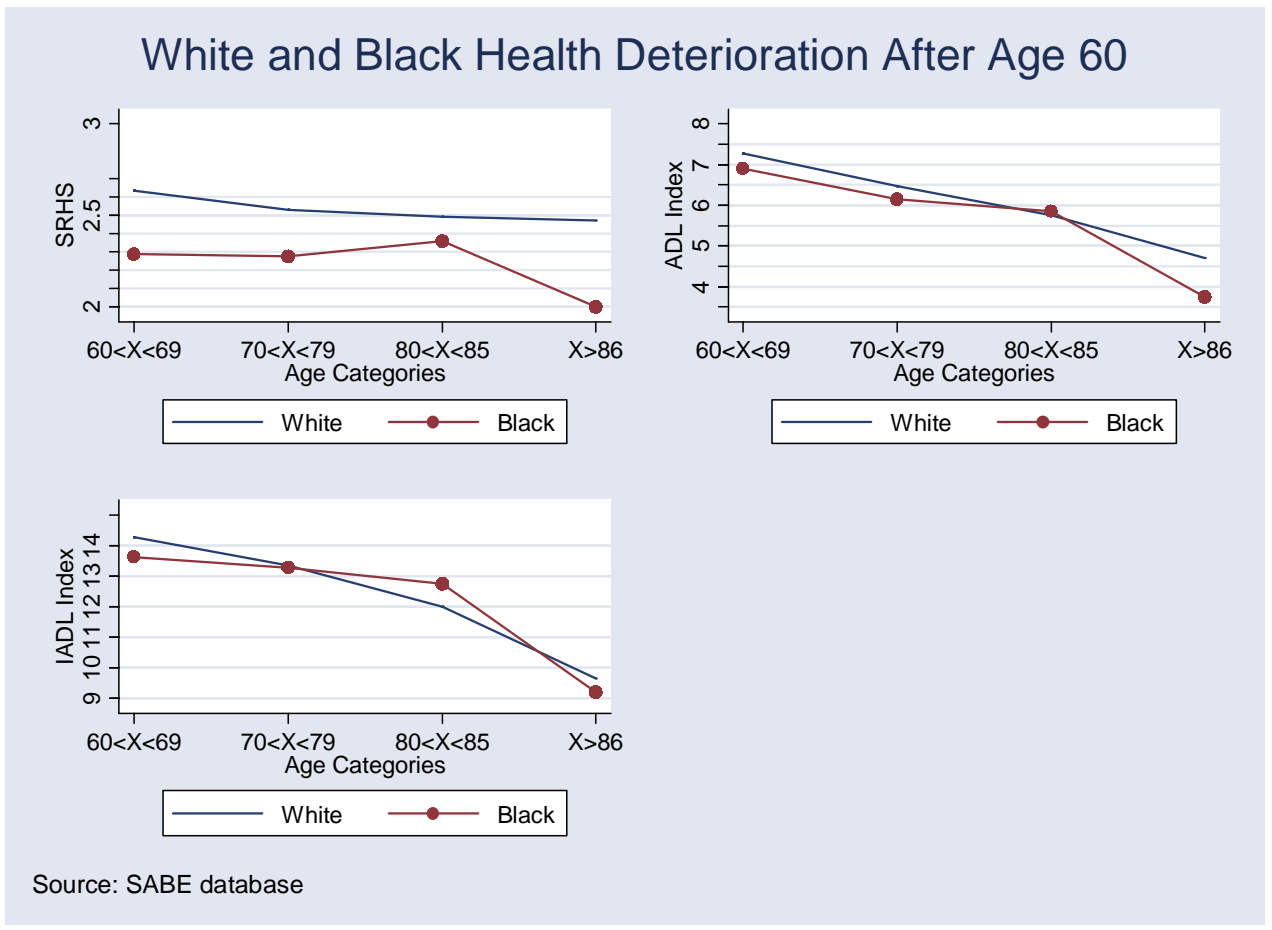

Figure 2: White and Black Health By Income Quartile

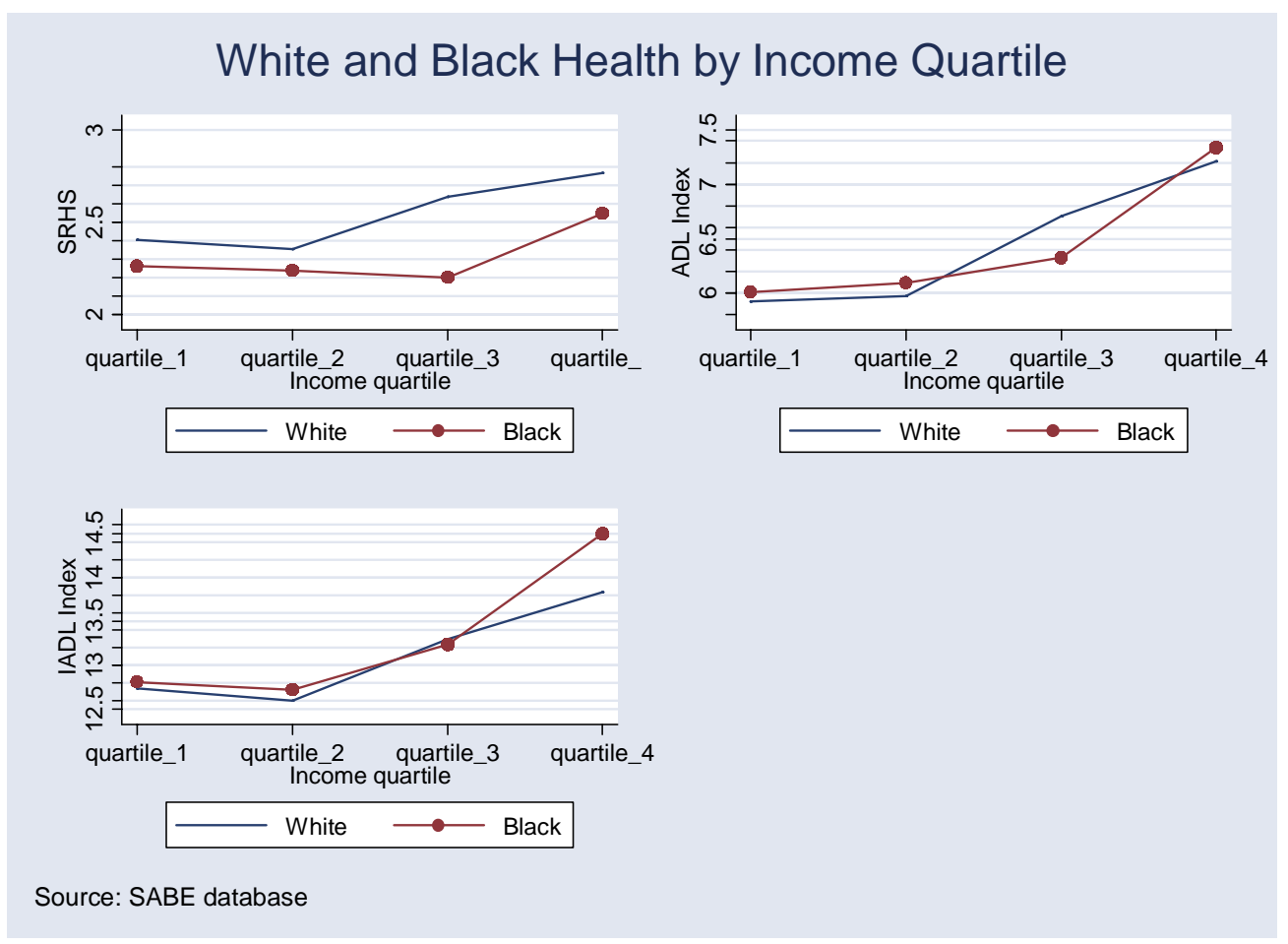


Figure 3: Comparison of White and Black Health Conditions

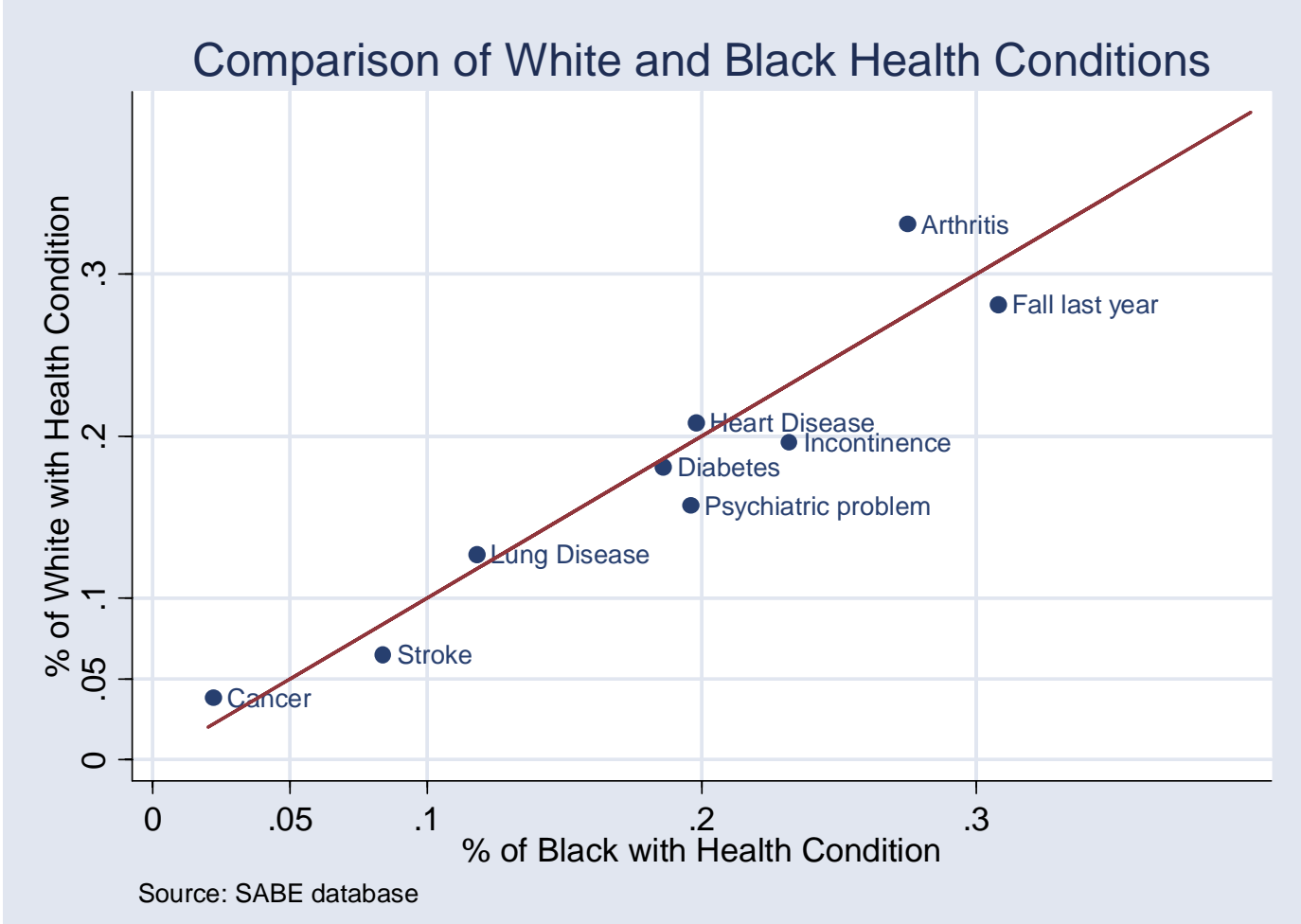


Table 1. Brazil

Comparison of White and Black health in old age

Weighted summary statistics.

\begin{tabular}{|c|c|c|c|c|}
\hline \multirow{3}{*}{ Health Indicators } & \multicolumn{4}{|c|}{ Males (765) } \\
\hline & \multicolumn{2}{|c|}{ White $(n=628)$} & \multicolumn{2}{|c|}{ Black $(n=137)$} \\
\hline & Mean & Std err & Mean & Std err \\
\hline \multicolumn{5}{|l|}{ Health functional status } \\
\hline Self-reported Health Status & 2.602 & $(0.046)$ & 2.362 & $(0.068)$ \\
\hline ADL index & 7.644 & $(0.136)$ & 7.211 & $(0.267)$ \\
\hline IADL index & 11.061 & $(0.116)$ & 9.403 & $(0.261)$ \\
\hline \multicolumn{5}{|l|}{ Life threatening conditions } \\
\hline Hypertension & 0.478 & $(0.023)$ & 0.589 & $(0.047)$ \\
\hline Diabetes & 0.171 & $(0.021)$ & 0.163 & $(0.038)$ \\
\hline Cancer & 0.038 & $(0.007)$ & 0.019 & $(0.015)$ \\
\hline Chronic Lung Disease & 0.146 & $(0.015)$ & 0.133 & $(0.032)$ \\
\hline Heart Disease & 0.217 & $(0.019)$ & 0.193 & $(0.038)$ \\
\hline Stroke & 0.078 & $(0.012)$ & 0.109 & $(0.027)$ \\
\hline \multicolumn{5}{|l|}{ Disabling conditions } \\
\hline Arthritis, Rheumatism or Osteoarthritis & 0.217 & $(0.019)$ & 0.144 & $(0.037)$ \\
\hline Fall in the last 12 months & 0.206 & $(0.022)$ & 0.253 & $(0.039)$ \\
\hline Incontinence & 0.091 & $(0.013)$ & 0.182 & $(0.032)$ \\
\hline Cognitive scores & 0.964 & $(0.008)$ & 0.857 & $(0.039)$ \\
\hline Emotional, Nervous or psychiatric problem & 0.126 & $(0.016)$ & 0.194 & $(0.038)$ \\
\hline \multicolumn{5}{|l|}{ Anthropometry measures } \\
\hline Height (cms) & 165.6 & $(0.336)$ & 164.9 & $(1.161)$ \\
\hline Weight (kgs) & 70.1 & $(0.685)$ & 69.3 & $(1.591)$ \\
\hline
\end{tabular}

\begin{tabular}{|c|c|c|c|}
\hline \multicolumn{4}{|c|}{ Females $(1,086)$} \\
\hline \multicolumn{2}{|c|}{ White $(n=894)$} & \multicolumn{2}{|c|}{ Black $(n=192)$} \\
\hline Mean & Std err & Mean & Std err \\
\hline 2.595 & $(0.035)$ & 2.221 & $(0.070)$ \\
\hline 6.351 & $(0.108)$ & 6.214 & $(0.187)$ \\
\hline 12.381 & (0.104) & 11.334 & $(0.235)$ \\
\hline 0.543 & $(0.017)$ & 0.631 & $(0.035)$ \\
\hline 0.187 & $(0.015)$ & 0.202 & $(0.029)$ \\
\hline 0.039 & $(0.006)$ & 0.024 & $(0.117)$ \\
\hline 0.114 & $(0.012)$ & 0.106 & $(0.025)$ \\
\hline 0.202 & $(0.016)$ & 0.202 & $(0.026)$ \\
\hline 0.057 & $(0.009)$ & 0.065 & $(0.023)$ \\
\hline 0.411 & $(0.017)$ & 0.373 & $(0.032)$ \\
\hline 0.334 & $(0.018)$ & 0.347 & $(0.032)$ \\
\hline 0.264 & $(0.014)$ & 0.267 & $(0.042)$ \\
\hline 0.941 & $(0.009)$ & 0.887 & $(0.022)$ \\
\hline 0.179 & $(0.015)$ & 0.198 & $(0.032)$ \\
\hline 151.9 & $(0.259)$ & 152.8 & $(0.424)$ \\
\hline 64.2 & $(0.597)$ & 63.1 & (1.316) \\
\hline
\end{tabular}

1) Self-reported Health Status was coded 5= Excellent, 4=Very Good, 3=Good, 2=Fair and 1=Poor

2) $\mathrm{ADL}$ is an indicator from 0 to $10(0=$ worst condition $)$

3) IADL is an indicator from 0 to 15 ( $0=$ worst condition $)$

4) Each health condition refers to whether a doctor or nurse ever told the individual that he or she had

the condition. A dummy indicator was constructed where $1=$ existence of the condition, 0 otherwise.

5) Cognitive score represents the percentage of individuals with an score higher than 13 (that is, in good cognitive condition) 
Table 2. Brazil

Income differences among White and Black in old age

Weighted Conditional Probability.

\begin{tabular}{|c|c|c|}
\hline Income Groups & $\begin{array}{l}\text { White }(\mathrm{n}=\mathbf{1 , 5 2 0}) \\
(\%)\end{array}$ & $\begin{array}{c}\text { Black }(\mathrm{n}=\mathbf{3 3 1}) \\
(\%)\end{array}$ \\
\hline \multicolumn{3}{|l|}{ Total Income } \\
\hline Quartile 1 & $28.65 \%$ & $29.86 \%$ \\
\hline Quartile 2 & $17.81 \%$ & $25.28 \%$ \\
\hline Quartile 3 & $23.89 \%$ & $29.17 \%$ \\
\hline Quartile 4 & $29.65 \%$ & $15.69 \%$ \\
\hline \multicolumn{3}{|l|}{ Total Wealth } \\
\hline Quartile 1 & $21.12 \%$ & $33.71 \%$ \\
\hline Quartile 2 & $23.76 \%$ & $31.03 \%$ \\
\hline Quartile 3 & $27.53 \%$ & $24.89 \%$ \\
\hline Quartile 4 & $27.58 \%$ & $10.37 \%$ \\
\hline
\end{tabular}

\section{Notes}

1) Income includes working and non-working income adjusted by household size

2) Wealth is based on a principal component index of assets in the household adjusted by household size 
Table 3. Brazil

Income and health differences among White and Black in old age

Weighted summary statistics.

\begin{tabular}{|c|c|c|c|c|}
\hline \multirow[t]{2}{*}{ Income Groups } & \multicolumn{4}{|c|}{ White $(n=1,520)$} \\
\hline & \multicolumn{2}{|c|}{ Self-reported health } & \multirow[t]{2}{*}{ ADL Index } & \multirow[t]{2}{*}{ IADL Index } \\
\hline Total Income & & & & \\
\hline Quartile 1 & 2.435 & $(0.051)$ & $6.274(0.139)$ & $13.279(0.149)$ \\
\hline Quartile 2 & 2.385 & $(0.050)$ & $6.313(0.186)$ & $13.076(0.193)$ \\
\hline Quartile 3 & 2.682 & $(0.058)$ & $7.183(0.156)$ & $13.883(0.134)$ \\
\hline Quartile 4 & 2.816 & $(0.054)$ & $7.586(0.191)$ & $14.225(0.124)$ \\
\hline \multicolumn{5}{|l|}{ Total Wealth } \\
\hline Quartile 1 & 2.419 & $(0.044)$ & $6.538(0.168)$ & $13.332(0.152)$ \\
\hline Quartile 2 & 2.441 & $(0.054)$ & $6.729(0.183)$ & $13.563(0.184)$ \\
\hline Quartile 3 & 2.685 & $(0.056)$ & 7.089 (0.186) & $13.736(0.143)$ \\
\hline \multirow[t]{3}{*}{ Quartile 4} & 2.783 & $(0.069)$ & $7.103 \quad(0.204)$ & $13.959(0.131)$ \\
\hline & \multicolumn{4}{|c|}{ Black $(n=331)$} \\
\hline & Self-repo & 1 health & ADL Index & IADL Index \\
\hline \multicolumn{5}{|l|}{ Total Income } \\
\hline Quartile 1 & 2.324 & $(0.105)$ & $6.461 \quad(0.321)$ & $13.065(0.303)$ \\
\hline Quartile 2 & 2.253 & $(0.078)$ & $6.382(0.405)$ & $13.198(0.378)$ \\
\hline Quartile 3 & 2.174 & $(0.069)$ & $6.633(0.368)$ & $13.344(0.434)$ \\
\hline Quartile 4 & 2.429 & $(0.109)$ & 7.309 (0.426) & $14.481(0.218)$ \\
\hline \multicolumn{5}{|l|}{ Total Wealth } \\
\hline Quartile 1 & 2.121 & $(0.079)$ & $6.339 \quad(0.277)$ & $13.273(0.327)$ \\
\hline Quartile 2 & 2.248 & $(0.061)$ & $6.681 \quad(0.233)$ & $13.124(0.258)$ \\
\hline Quartile 3 & 2.376 & $(0.087)$ & $6.698(0.274)$ & $13.793(0.257)$ \\
\hline Quartile 4 & 2.653 & $(0.159)$ & $7.217 \quad(0.579)$ & $13.739(0.828)$ \\
\hline
\end{tabular}

\section{Notes}

1) Standard errors in parentheses

2) Self-reported Health Status was coded $5=$ Excellent, $4=$ Very Good, $3=$ Good, $2=$ Fair and $1=$ Poor

3) $\mathrm{ADL}$ is an indicator from 0 to $10(0=$ worst condition), and IADL is an indicator from 0 to $15(0=$ worst condition $)$

4) Income includes working and non-working income adjusted by household size

5) Wealth is based on a principal component index of assets in the household adjusted by household size 
Table 4. Brazil

Health and wealth differences among White and Black in old age

Weighted summary statistics.

\begin{tabular}{lcccc}
\hline Health Indicators & \multicolumn{2}{c}{ Wealth } & \multicolumn{2}{c}{ Wealth } \\
& \multicolumn{2}{c}{ White $(\mathbf{n = 1 , 5 2 0})$} & & \\
& \multicolumn{3}{c}{ Black $(\mathbf{n}=\mathbf{3 3 1})$} \\
\hline SRHS & -0.363 & $(0.104)$ & -0.863 & $(0.297)$ \\
$\quad$ Poor & -0.009 & $(0.054)$ & -0.446 & $(0.117)$ \\
$\quad$ Fair & 0.058 & $(0.075)$ & -0.232 & $(0.229)$ \\
Good & 1.032 & $(0.318)$ & 0.329 & $(0.551)$ \\
$\quad$ Very Good & 0.318 & $(0.147)$ & 0.209 & $(0.072)$ \\
$\quad$ Excellent & & & &
\end{tabular}

1) Self-reported Health Status was coded $5=$ Excellent, $4=$ Very Good, $3=$ Good, $2=$ Fair and 1=Poor

2) Higher number on the wealth index indicates wealthier individuals according to assets 
Table 5. Brazil

Comparison of White and Black demographic, socio-economic, family support and baseline health characteristics in old age Weighted summary statistics of selected variables.

\begin{tabular}{|c|c|c|c|c|}
\hline \multirow[t]{2}{*}{ Variables } & \multicolumn{2}{|c|}{ White $(\mathrm{n}=1,520)$} & \multicolumn{2}{|c|}{ Black $(n=331)$} \\
\hline & Mean & Std err & Mean & Std err \\
\hline \multicolumn{5}{|l|}{ Individual characteristics } \\
\hline Age & 69.654 & $(0.431)$ & 67.876 & $(0.492)$ \\
\hline Gender (Female) & 0.584 & $(0.014)$ & 0.585 & $(0.032)$ \\
\hline Born in Brazil & 0.896 & $(0.013)$ & 0.999 & $(0.001)$ \\
\hline Living alone & 0.141 & $(0.013)$ & 0.147 & $(0.024)$ \\
\hline Total children alive & 2.549 & $(0.084)$ & 2.805 & $(0.102)$ \\
\hline Currently married & 0.577 & $(0.022)$ & 0.508 & $(0.036)$ \\
\hline \multicolumn{5}{|l|}{ Socio-Economic conditions } \\
\hline Literacy & 0.842 & $(0.017)$ & 0.618 & $(0.032)$ \\
\hline Education & 1.381 & $(0.061)$ & 1.056 & $(0.028)$ \\
\hline Age of retirement & 2.042 & $(0.045)$ & 2.179 & $(0.087)$ \\
\hline Home ownership & 1.221 & $(0.021)$ & 1.233 & $(0.044)$ \\
\hline Vehicle ownership & 0.486 & $(0.023)$ & 0.324 & $(0.032)$ \\
\hline Availability of private health insurance & 0.051 & $(0.009)$ & 0.03 & $(0.011)$ \\
\hline \multicolumn{5}{|l|}{ Family Support } \\
\hline Number of household members & 2.963 & $(0.073)$ & 3.661 & $(0.171)$ \\
\hline Number of brothers and sisters & 2.981 & $(0.095)$ & 3.363 & $(0.231)$ \\
\hline Number of dependents on senior's total income & 2.293 & $(0.056)$ & 2.681 & $(0.146)$ \\
\hline \multicolumn{5}{|l|}{ Baseline health status } \\
\hline Living in rural areas first 5 years of life & 0.558 & $(0.029)$ & 0.749 & $(0.033)$ \\
\hline Smoking & 0.608 & $(0.021)$ & 0.743 & $(0.043)$ \\
\hline Family economic condition during the first 15 years of life & 1.017 & $(0.031)$ & 0.911 & $(0.049)$ \\
\hline Self-assessment of individual's health in the first 15 years of life & 1.451 & $(0.024)$ & 1.375 & $(0.046)$ \\
\hline Starvation in the first 15 years of life & 0.177 & $(0.012)$ & 0.267 & $(0.026)$ \\
\hline
\end{tabular}

1) Total children included biological children, step-children and adopted children

2) Smoking was code $0=$ never smoke, $1=$ past smoker, $2=$ current smoker

3) Economic condition during the first 15 years of life was coded $0=$ Poor, $1=$ Average, and $2=$ Above average

4) Self-assessment of health during the first 15 years of life was coded $0=$ Poor, $1=$ Good, and $2=$ Excellent

5) Education was coded $0=$ Elementary, $1=$ Secondary, 2 Technical and $3=$ College

6) Education was coded $0=$ Elementary, $1=$ Secondary, 2 Technical and $3=$ College

7) Age of retirement was coded $0=$ under fifties, $1=$ fifties, $2=$ sixties, and $3=$ seventies and above

8) Home ownership was coded $1=$ own, $2=$ rent and $3=$ own by other 


\section{Table 6. Brazil}

Description of variables in the SABE Database

\begin{tabular}{|c|c|}
\hline Variables & Description \\
\hline \multicolumn{2}{|l|}{ Dependent Variables } \\
\hline Cognitive evaluation & $\begin{array}{l}\text { A vector of } 10 \text { different variables (e.g., memory at the present time, able to manage money, } \\
\text { shopping alone, remember family events, etc). }\end{array}$ \\
\hline Self-reported health status & A question that includes the following options: excellent, very good, good, fair, and poor. \\
\hline $\begin{array}{l}\text { Existence of chronic and } \\
\text { acute conditions }\end{array}$ & $\begin{array}{l}\text { Different questions about the existence of hypertension, diabetes, cancer, lung disease, } \\
\text { heart attack, coronary heart disease, angina, or other heart problems, cerebral embolism, } \\
\text { arthritis, rheumatism, or osteoarthritis. }\end{array}$ \\
\hline ADL / IADL scores & $\begin{array}{l}\text { Variables to measure current ADL and IADL scores. This excludes any difficulties that an } \\
\text { individual expects to last more than three months. }\end{array}$ \\
\hline Mental Health & Variables to measure emotional, nervous or psychiatric problems in the last 12 months \\
\hline Health Risk Factors & Smoking, drinking, and eating behaviors \\
\hline Medical Care Use & Several questions which capture hospital, outpatient, and preventive care use \\
\hline \multicolumn{2}{|l|}{ Independent Variable } \\
\hline Skin & $\begin{array}{l}\text { Includes the following categories: White, Mestizo (combination of white and indigenous), Mulatto } \\
\text { (combination of black and white), Black, Indigenous, Asian, Other. }\end{array}$ \\
\hline \multicolumn{2}{|l|}{ Control Variables } \\
\hline $\begin{array}{l}\text { Vector of current demographic } \\
\text { characteristics }\end{array}$ & $\begin{array}{l}\text { Age, gender, religion, immigration status, living with someone, number of children, number of step-children, } \\
\text { total number of individuals in the household, number of an individual's children not living at home, } \\
\text { number of brothers and sisters, age cohort, current marital status, number of marriages, } \\
\text { duration of each marriage, characteristics of each transition in marital status in the individual's life. }\end{array}$ \\
\hline $\begin{array}{l}\text { Vector of current socio-economic } \\
\text { characteristics }\end{array}$ & $\begin{array}{l}\text { Level of schooling, illiteracy, age when started to work, current work status, age at } \\
\text { retirement, type of occupation, total income from different sources (pension, } \\
\text { family transfers, banking income, welfare subsidy), total expenditures on goods, } \\
\text { home characteristics, home ownership, list of household assets (e.g..., refrigerator, washer, } \\
\text { water heater, microwave, television, telephone, VCR, radio player, heating, air conditioning, fan), } \\
\text { availability of social security, private insurance, other public insurance. }\end{array}$ \\
\hline Vector of family of support & $\begin{array}{l}\text { Number of members in the household, number of sibblings, number of children who live outside home, } \\
\text { and other family and friends }\end{array}$ \\
\hline Vector of baseline health status & $\begin{array}{l}\text { Father or mother alive, father or mother's age at death, living in rural areas first } 5 \text { years of life } \\
\text { age when first diagnosed with cancer, past smoker, current smoker, family economic condition during the } \\
\text { first } 15 \text { years of life, self-assessment of individual's health in the first } 15 \text { years of life, existence of any } \\
\text { of the following illnesses during the first } 15 \text { years of life: kidney disease, hepatitis, measles } \\
\text { tuberculosis, rheumatic fever, asthma, bronchitis. }\end{array}$ \\
\hline
\end{tabular}


Table 7. Brazil

OLS estimates of the effects of skin (proxy for race) on health status in old age

Skin coefficient and standard error. Weighted sample $(\mathrm{N}=\mathbf{1 , 8 5 1})$

\begin{tabular}{|c|c|c|c|c|c|c|c|c|}
\hline \multirow{2}{*}{$\begin{array}{l}\text { Vector Included } \\
\text { I) Only the skin variable included }\end{array}$} & \multicolumn{3}{|c|}{ Self-reported health } & \multicolumn{2}{|c|}{ ADL Index } & \multicolumn{3}{|c|}{ IADL Index } \\
\hline & -0.329 & $(0.048)$ & $* * *$ & -0.255 & $(0.185)$ & -0.264 & $(0.189)$ & \\
\hline R_Squared & 0.03 & & & 0.002 & & 0.001 & & \\
\hline F-value & 46.57 & & $* * *$ & 1.90 & & 1.95 & & \\
\hline II) Vector of individual characteristics & -0.305 & $(0.053)$ & $* * *$ & -0.352 & $(0.176)$ & -0.383 & $(0.187)$ & $* *$ \\
\hline R_Squared & 0.04 & & & 0.12 & & 0.13 & & \\
\hline F-value & 12.47 & & $* * *$ & 26.46 & $* * *$ & 24.68 & & $* * *$ \\
\hline III) Vector of socio-economic conditions & -0.211 & $(0.046)$ & $* * *$ & -0.215 & $(0.159)$ & -0.206 & $(0.152)$ & \\
\hline R_Squared & 0.13 & & & 0.16 & & 0.15 & & \\
\hline F-value & 7.31 & & $* * *$ & 17.64 & $* * *$ & 13.95 & & $* * *$ \\
\hline IV) Vector of family support conditions & -0.282 & $(0.051)$ & $* * *$ & -0.294 & $(0.175) *$ & -0.273 & $(0.186)$ & \\
\hline R_Squared & 0.05 & & & 0.13 & & 0.16 & & \\
\hline F-value & 7.83 & & $* * *$ & 15.35 & $* * *$ & 22.53 & & $* * *$ \\
\hline V) Vector of baseline health conditions & -0.239 & $(0.052)$ & $* * *$ & -0.256 & $(0.173)$ & -0.269 & $(0.188)$ & \\
\hline R_Squared & 0.08 & & & 0.13 & & 0.14 & & \\
\hline F-value & 12.65 & & $* * *$ & 12.41 & $* * *$ & 13.84 & & $* * *$ \\
\hline VI) All variables included & -0.164 & $(0.050)$ & $* * *$ & -0.113 & $(0.164)$ & -0.052 & $(0.154)$ & \\
\hline R_Squared & 0.15 & & & 0.18 & & 0.18 & & \\
\hline F-value & 22.01 & & $* * *$ & 20.09 & $* * *$ & 8.45 & & $* * *$ \\
\hline
\end{tabular}

(**) significant at $\mathbf{p}<0.05,(* * *)$ significant at $\mathbf{p}<0.01$

Notes

1) Skin was coded $0=$ White, $1=$ Black; Self-reported Health Status was coded $5=$ Excellent, $4=$ Very Good, 3=Good, 2=Fair and $1=$ Poor

2) IADL is an indicator from 0 to $15(0=$ worst condition) and ADL is an indicator from 0 to 10 ( $0=$ worst condition)

3) Each regression includes a vector of basic individual characteristics such as: age, gender, living alone, married, immigrant, and total children alive

4) The vector of socio-economic condition includes: level of schooling, literacy, age when started to work, age at retirement, type of occupation total income from different sources, home characteristics, home ownership, wealth index, and availability of health insurance

5) The vector of family support includes: number of household members, number of brothers and sisters, number of children living outside home

6) The vector of baseline health includes: living in rural areas first 5 years of life, economic condition during the first 15 years of life,

self-assessment of health in the 15 years of life, existence of a serious health problem during the first 15 years of life 
Table 8. Brazil

OLS estimates of the determinants of health status in old age

Selected coefficients and standard error. Weighted sample $(\mathrm{N}=1,851)$

\begin{tabular}{|c|c|c|c|c|}
\hline \multirow[b]{3}{*}{ Variables } & \multicolumn{4}{|c|}{ Self-reported health } \\
\hline & \multicolumn{2}{|c|}{ White } & \multicolumn{2}{|c|}{ Black } \\
\hline & Coeff. & (S.E.) & Coeff. & (S.E.) \\
\hline Constant & 2.741 & $(0.341) * * *$ & 1.434 & $(0.715) * *$ \\
\hline \multicolumn{5}{|l|}{ Individual Characteristics } \\
\hline Age & -0.0001 & $(0.004)$ & 0.010 & $(0.005)$ \\
\hline Female & 0.016 & $(0.057)$ & -0.093 & $(0.101)$ \\
\hline Immigrant & 0.206 & $(0.083) * *$ & 0.459 & $(0.535)$ \\
\hline Married & -0.089 & $(0.064)$ & 0.058 & $(0.122)$ \\
\hline \multicolumn{5}{|l|}{ Socio-economic condition } \\
\hline Wealth & 0.038 & $0.018 * *$ & 0.053 & $(0.032)$ \\
\hline \multicolumn{5}{|l|}{ Education (Elementary ) } \\
\hline Secondary & 0.234 & $(0.121)$ & 0.194 & $(0.493)$ \\
\hline Technical & 0.439 & $(0.134) * * *$ & 0.087 & $(0.202)$ \\
\hline College & 0.076 & $(0.104)$ & 0.128 & $(0.231)$ \\
\hline \multicolumn{5}{|l|}{ House ownership (own) } \\
\hline Rent & -0.135 & $(0.106)$ & -0.369 & $(0.105) * * *$ \\
\hline Other & 0.031 & $(0.118)$ & -0.171 & $(0.157)$ \\
\hline Working & 0.278 & $(0.066) * * *$ & 0.214 & $(0.113)$ \\
\hline \multicolumn{5}{|l|}{ Family support } \\
\hline \multicolumn{5}{|l|}{ Household members (single) } \\
\hline Two individuals & -0.088 & $(0.104)$ & -0.077 & $(0.149)$ \\
\hline Three-to-five & -0.175 & $(0.103)$ & -0.084 & $(0.161)$ \\
\hline More than five & -0.319 & $(0.124) * *$ & -0.142 & $(0.156)$ \\
\hline \multicolumn{5}{|l|}{ Baseline health conditions } \\
\hline Living in rural area first 5 yrs & -0.237 & $(0.062) * * *$ & -0.235 & $(0.128)$ \\
\hline \multicolumn{5}{|c|}{ Economic status first 15 yrs (poor) } \\
\hline Average & -0.047 & $(0.077)$ & -0.021 & $(0.145)$ \\
\hline Above average & -0.018 & $(0.078)$ & 0.085 & $(0.150)$ \\
\hline Starvation during first $15 \mathrm{yrs}$ & -0.109 & $(0.075)$ & -0.144 & $(0.139)$ \\
\hline R-squared & 0.13 & & 0.20 & \\
\hline F-value & 18.56 & $* * *$ & 7.82 & $* *$ \\
\hline
\end{tabular}

\begin{tabular}{|c|c|c|c|}
\hline \multicolumn{4}{|c|}{ ADL Index } \\
\hline \multicolumn{2}{|c|}{ White } & \multicolumn{2}{|c|}{ Black } \\
\hline Coeff. & (S.E.) & Coeff. & (S.E.) \\
\hline 13.516 & $(0.878) * * *$ & 9.015 & $1.951 * * *$ \\
\hline-0.075 & $(0.009) * * *$ & -0.046 & $(0.019) * *$ \\
\hline-1.174 & $(0.151) * * *$ & -0.687 & $(0.312) * *$ \\
\hline 0.054 & $(0.211)$ & 1.292 & $(0.905)$ \\
\hline-0.249 & $(0.185)$ & 0.116 & $(0.363)$ \\
\hline 0.055 & $(0.045)$ & 0.019 & $(0.105)$ \\
\hline-0.065 & $(0.302)$ & 1.595 & $(0.562)$ \\
\hline 0.441 & $(0.384)$ & -0.194 & (1.883) \\
\hline-0.121 & $(0.279)$ & 0.325 & $(0.638)$ \\
\hline-0.343 & $(0.255)$ & -0.046 & $(0.361)$ \\
\hline 0.161 & $(0.296)$ & -0.761 & $(0.579)$ \\
\hline 0.756 & $(0.155) * * *$ & 0.907 & $(0.361) * *$ \\
\hline
\end{tabular}

\begin{tabular}{|c|c|c|c|}
\hline-0.233 & $(0.276)$ & 0.137 & $(0.636)$ \\
\hline-0.474 & $(0.275)$ & -0.141 & $(0.687)$ \\
\hline-0.686 & $(0.404)$ & -0.807 & $(0.919)$ \\
\hline-0.377 & $(0.127) * * *$ & -0.209 & $(0.377)$ \\
\hline 0.014 & $(0.217)$ & 0.507 & $(0.594)$ \\
\hline 0.126 & $(0.215)$ & 0.248 & $(0.524)$ \\
\hline-0.347 & $(0.197)$ & 0.222 & $(0.443)$ \\
\hline 0.18 & & 0.17 & \\
\hline 9.40 & & 6.12 & $* *$ \\
\hline
\end{tabular}

(**) significant at $\mathbf{p}<0.05,(* * *)$ significant at $\mathbf{p}<0.01$

Notes

1) In parentheses the excluded categories

2) Variables included but not shown: total number of children alive, living alone, number of brother and sisters, availability of insurance

Literacy, type of occupation in the past, age began working, age of retirement, number of rooms, health status first 15 years of life 
Table 9. Brazil

Oaxaca-Blinder Decomposition of the differences in health between Whites and Blacks in old age

Weighted sample $(\mathrm{N}=\mathbf{1 , 8 5 1})$

\section{Oaxaca-Blinder}

I) Variation in health attributable to Self-reported health ADL index IADL index

all explanatory variables

II) Unexplained differences in health

a) Variation in health attributable to

14.6

11.2

8.8

the coefficients

$15.8 \quad 11.6 \quad-2.2$

b) Variation in health attributable to

$-438.5$

differences between model constants

130.7

450.1

$-449.9$

III) Total difference in health (I + II)

30.4

22.8

6.6

Percentage of the difference attributable

$48.0 \%$

$49.1 \%$

$133.3 \%$

to observable individual characteristics (I/III)

Percentage of the difference not attributable

$52.0 \%$

$50.9 \%$

$-33.3 \%$

to observable individual characteristics (II/III)

\section{Notes}

1) A positive number indicates advantage to Whites while a negative number indicates advantage to Blacks

2) All regressions include the following vectors: individual characteristics; socio-economic conditions;

family support; and baseline health

3) Results are based on OLS estimates 
Table 10. Brazil

Oaxaca-Blinder Decomposition of the differences in health by Income groups between Whites and Blacks in old age Weighted sample

\begin{tabular}{|c|c|c|c|}
\hline \multirow[b]{2}{*}{ Oaxaca-Blinder } & \multicolumn{3}{|c|}{ Upper Half of Income Distribution ( $N=964)$} \\
\hline & Self-reported health & ADL index & IADL index \\
\hline $\begin{array}{l}\text { I) Variation in health attributable to } \\
\text { all explanatory variables }\end{array}$ & 12.2 & -9.8 & -14.6 \\
\hline $\begin{array}{l}\text { II) Unexplained differences in health } \\
\text { a) Variation in health attributable to } \\
\text { the coefficients }\end{array}$ & $\begin{array}{l}32.2 \\
-71.6\end{array}$ & $\begin{array}{c}55.8 \\
-219.8\end{array}$ & $\begin{array}{c}28.5 \\
-760.9\end{array}$ \\
\hline $\begin{array}{l}\text { b) Variation in health attributable to } \\
\text { differences between model constants }\end{array}$ & 103.8 & 275.6 & 789.4 \\
\hline III) Total difference in health (I + II) & 44.4 & 46.0 & 13.9 \\
\hline $\begin{array}{l}\text { Percentage of the difference attributable } \\
\text { to observable individual characteristics (I/III) }\end{array}$ & $27.5 \%$ & $-21.3 \%$ & $-105.0 \%$ \\
\hline $\begin{array}{l}\text { Percentage of the difference not attributable } \\
\text { to observable individual characteristics (II/III) }\end{array}$ & $72.5 \%$ & $121.3 \%$ & $205.0 \%$ \\
\hline
\end{tabular}

\begin{tabular}{ccc}
\hline \multicolumn{3}{c}{ Lower Half of Income Distribution (N=887) } \\
\hline Self-reported health & ADL index & IADL index \\
\hline 14.1 & 10.5 & 23.6 \\
& & \\
-1.9 & -27.7 & -49.8 \\
-113.3 & -579 & -555.2 \\
& & \\
111.4 & 551.3 & 505.4 \\
& & \\
12.2 & -17.2 & -26.2 \\
\hline $115.6 \%$ & $-61.0 \%$ & $-90.1 \%$ \\
$-15.6 \%$ & $161.0 \%$ & $190.1 \%$ \\
\hline
\end{tabular}

\section{Notes}

1) A positive number indicates advantage to Whites while a negative number indicates advantage to Blacks

2) All regressions include the following vectors: individual characteristics; socio-economic conditions;

family support;and baseline health

3) Results are based on OLS estimates 